\title{
Object Sensing and its Identification \& Motion Sensing
}

\author{
S.Theivasigamani, Mary Linda, S. Amudha
}

\begin{abstract}
In Today's world, we usually see and deal with many visuals like, every time you look at something or somewhere, there is a visual at your sight but, "what are all these visuals?" In simple terms, these are nothing but images at that particular point of time. Now let's see how these are differentiated, and as far as we are concerned with visuals, we usually deal with them in the form of images. Each visual or a sight at that point of time can be considered as an image or a set of images. But here a question arises that "how do we really recognize an object or a thing and how do we actually differentiate between them and the answer obvious that's the human brain which is one among the exiting wonders of the world. As we all know a human brain does many exceptional functions which are not possible without its existence, And some of which cannot be completely replaced by any other artificial means, the fact is that there are some of its functions which actually seem so complex for humans to understand and therefore even in this very 20th century we are still unable to replace humans in some functions, as our science is still limited in some of its fields. But we all know that, more the number of robots that can replace a human in doing the tasks the better the output we get, there is a great need for human replacement in today world as time, resources come to a minimum when we start replacing human beings. Here in this paper we are dealing with object recognition as in today life this has become a challenge in science.
\end{abstract}

Keywords : human brain, human replacement, functions

\section{INTRODUCTION}

On account of sleuthing the closeness of a thing passing by on a vehicle, the finish of a door, or the arrival of a transporter puck at a stop, object ID is a fundamental endeavor in the computerization business. Present day controls masters and PC code engineers must be obliged to always observe once a thing or target has arrived, or been put, at a specific territory[1],[3],[5]. Event based programming may be a typical association and prerequisites these commitments at unequivocal concentrations inside the machine's pc or ladder method of reasoning PLC program While distinguishing contraptions don't live accurately, take a gander at or assess the thing in any capacity, they need to always pass on the closeness or nonattendance of their goal to the machine's structure by methods for electronic banner.

Revised Manuscript Received on July 22, 2019.

S.Theivasigamani, Department of CSE, Bharath Institute of Higher Edccation and Research, Chennai, Tamilnadu, India Email : dheiva94@gmail.com@gmail.com

Mary Linda, Department of CSE, Bharath Institute of Higher Edccation and Research, Chennai, Tamilnadu, India Email: catchlin.18@gmail.com

Ms. S. Amudha, Department of CSE, Bharath Institute of Higher Edccation and Research, Chennai, Tamilnadu, India amudha17s@gmail.com
There are different articles in distinguishing innovations.Seven of the principal essential among them will be referenced underneath, near a short depiction of their rectification is not possible action, preferences and objectives.

\section{A. Electro-Mechanical}

This essential sensor is an electromechanical cutoff switch. These gadgets contain a delicate small scale switch that changes state when a mechanical actuator is dislodged by the recognized article[2 ],[4],[6]. Rollers, stubbles and switches are a portion of the actuator renditions offered by a wide range of makers. Likewise, physical contact with the objective item isn't constantly alluring . review.

\section{B. Magnetic}

Attractive sensors are activated by the nearness of a perpetual magnet inside their detecting range[7], [9] ,[11]. Two distinctive working standards are normally utilized, either a reed contact or a Hall impact transducer. The disappointment rate of reed switches is moderately high, such a large number of architects are indicate Hall impact sensors when conceivable.

\section{Inductive}

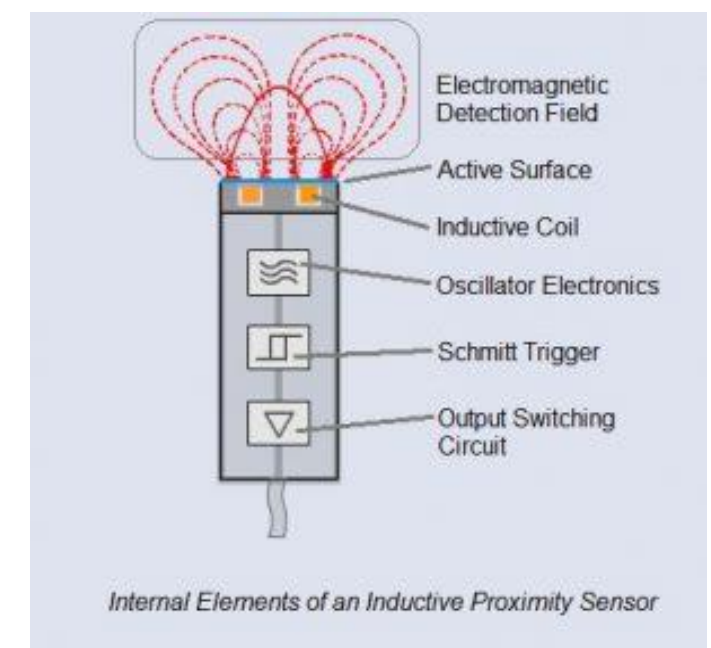

- These nearby buttons recognize metallic objects that cause an disruption of the sensor's life in the electromagnetic field. Separate strong identity varies depending on the type of metal and the measurement of metal within the scope of the sensor. These detectors come in many dimensions and forms. They are completely robust and knowledgeable ; therefore, they constitute a significant amount of the detectors used in mechanization and hardware processing. 


\section{Object Sensing And Its Identification \& Motion Sensing}

\section{Photoelectric Sensor Types}

On account of sleuthing the closeness of a thing passing by on a vehicle, the finish of a door, or the arrival of a transporter puck at a stop, object ID is a fundamental endeavor in the computerization business. Present day controls masters and PC code engineers must be obliged to always observe once a thing or target has arrived, or been put, at a specific territory. Event based programming may be a typical association and prerequisites these commitments at unequivocal concentrations inside the machine's pc or ladder method of reasoning PLC program [32],[34],[36]

While distinguishing contraptions don't live accurately, take a gander at or assess the thing in any capacity, they need to always pass on the closeness or nonattendance of their goal to the machine's structure by methods for electronic banner. There are different articles in distinguishing innovations. Seven of the principal essential among them will be referenced underneath, near a short depiction of their action, preferences and objectives.

\section{E. Ultrasonic}

Regularly, these gadgets transmit a short burst of ultrasonic sound to an objective that mirrors the sound back to the sensor[26],[28],[30]. The sound wave is very much reflected by practically all thick materials (metal, wood, plastic, glass, fluid, and so on.) and isn't influenced by shading, straightforward or sparkling items. All these are the prexisting innovations yet here would see another innovation dependent on PC vision or in different terms picture acknowledgment.

\section{F. Scope of the Project}

Several future changes can be made to the system. The detection, tracking and counting of vehicles can be extended to real-time live feeds. Apart from the detection and extraction, process of recognition can also be done during the same time. By using these recognition techniques, the vehicles can be classified accordingly[13], [15],[ 17] . Recognition techniques would also require some additional database to match with the given vehicle. The system is designed for the detection and tracking and counting of a multiple moving vehicle. It can be further devised to alarming system.

\section{G. Existing System}

Presently there is no proper use of this technology as image recognition is not fully used at its maximum extent many places this is still an experimental idea[31],[33],[35]. And in terms of implementation it is much worst then the previous case as there is no proper implementation of this very important technology so we usually do all the things related to identification manually and we don't prefer to relay on devices for this need and this manual process is not easy as we know as lot of man power is needed and even accuracy is not up to the mark[37],[39],[41]
Excluding this popularly used technique we have some other techniques which can reduce manpower at a small extend and can there by replace human for some limited functions like the famous ultrasonic way of object sensing as we have already heard of, but has its own limitations and next you can even follow thermal detection this the way in which you can identify the objects with respect to their heat i.e. Identifying the temperature. And you have the capacitor technique magnetic technique, inductive technique and few more but all these are full of complications and limitation so that's the reason there no proper accuracy and more limitations.

\section{H. Disadvantage of Existing System}

As we have said previously system the widely used way for this object detection or identification is usually manual that mean there is no proper accuracy because of manual errors which are so common as a human.

- Due to manual identification there is a need for manpower which is so annoying because as lot of time and human labor is used for these types of work

- As discussed earlier we even have some electronic based devices but there are lot of limitations and less accuracy and these not fully automated.

\section{PROPOSED SYSTEM}

A proper use of related technology should be done during every situation and this what we are doing here, as we are seeing many complications and inaccuracy in the previously followed technique here, we are planning to replace this with the help of some devices like a computer to process the image and the software for image identification and motion sensing so that the work of identification can be done without the need of humans by a automated computer which has the software already pre-installed in it so as to process the image and there by providing the information[8],[ 10],[12]

In this system we mainly need few things which include, a computer like raspberry pie which a very small computer with the help of which we can take the input and output and a hardware for it which is camera which is further connected to the device. And mainly the software called Open CV which is the one who has to take the data that is raw data and identify data required and should send the output results as asked by the computeR[14],[16], [18]

Open CV has many already prebuilt libraries so almost all the necessary functions and the task can be acquired almost with in no time[38],[40]. And coming to its most prominent real life use the right place for this technology is in traffic maintenance and surveillance, as constant monitoring is very important in the traffic by police men and due this manual errors are common or in other words negligence is possible and also human resource is also saved by our proposal[19],[21],[23]. 
They consist of the associated sections: the basis with no moving articles and the moving objects scene. The structure is designed to find the moving objects boundary and identify the amount of shifting papers from the video scene. The item recognition and checking framework comprises of six noteworthy segments: 1) Image Acquisition 2) Image Enhancement 3) Image Segmentation 4) Image Analysis 5) Object Counting, and 6) Reports.

\section{A. Advantages of Proposed System}

Compared to a lot of its predecessors, which are full of limitations and errors, this newly proposed system is really useful as the reasons given before.

- Cost efficiency as the device is small computer with a digital camera hardware. And a program for processing the data is only enough.

- Proper statistics can be taken this this system and there by this information can be used for further use to control the traffic.

- This same technology can also be used for security purposes like identification of vehicles etc.

\section{B. MODULES DESCRIPTION}

\section{List of Modules}

- Raspberry pi computer

- An operating system installed like python etc.

- Camera device

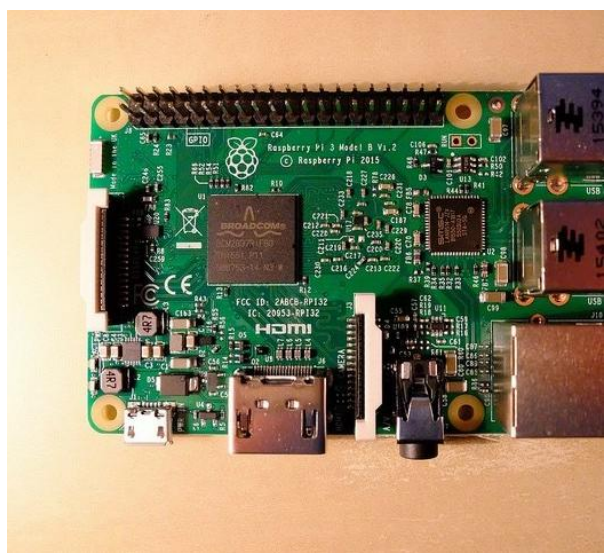

1. Raspberry pi computer

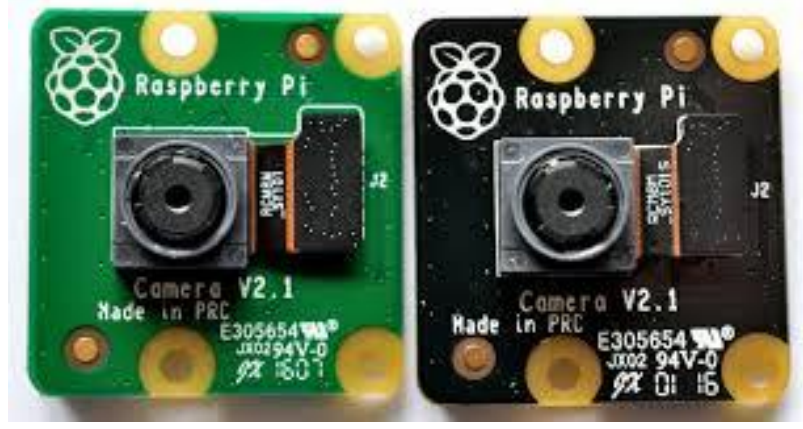

\section{Camera module}

-

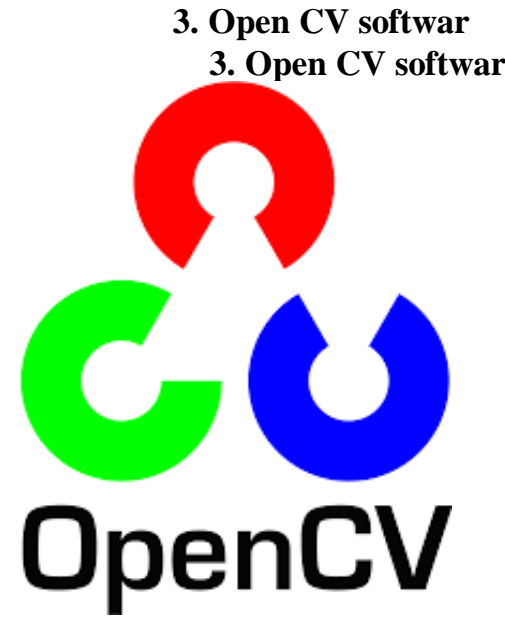

3. Open CV software

\section{MODULES DESCRIPTION}

Raspberry Pi: It is a machine of credit card size initially intended for education, influenced by the BBC Micro of 1981. The objective of Creator Eben Upton was to produce a low-cost tool that would enhance pre-university level programming abilities and hardware knowledge. But thanks to its tiny size and affordable cost, it was rapidly embraced for initiatives that involve more than other fundamental microcontrollers by buyers, manufacturers and electronics lovers. (such as Arduino devices etc).

The Raspberry Pi is a bit slower than a modern laptop or desktop but is still a complete Linux computer and so it can provide all the expected abilities that implies, at a low-power consumption level. [20], [22], [24]

2. OpenCV: (Open Source Computer Vision) is a library of programming features primarily directed at real-time computer vision.[1 ] Originally created by Intel, it was subsequently endorsed by Willow Garage then Itseez (which was subsequently purchased by Intel. The library is cross-platform and free to use under the open-source BSD license.

OpenCV supports the deep learning frameworks TensorFlow, Torch/ PyTorch and Caffe.

3.Camera module: A camera module is an embedded picture detector with a lens, control electronics, and an interface such as CSI, Ethernet, or simple low-voltage differential signals.

\section{Published By:}



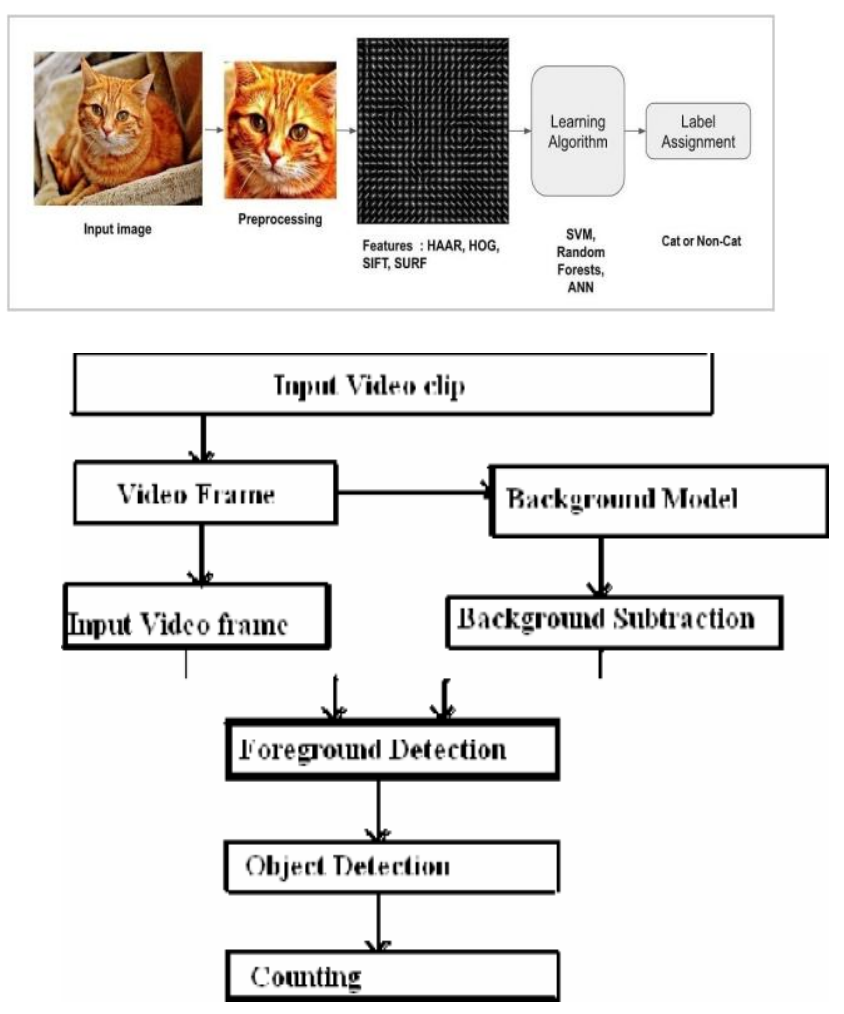

\section{IMPLEMENTATION AND EXPECTED RESULTS MOVING OBJECT DETECTION ALGORITHMS}

In this chapter, we develop object tracking algorithms that are introduced step by step to detect border frames, write chain instructions, and detect borders in border frames, where the border block is described as a block comprising limits of a favorable moving object. [25],[27],[29]

\section{A. Boundary Block Detection}

At the point when this condition is disregarded, the irregularity of movement vector field exist and suggest the presence of the limit in related square.

This journal uses double-blind review process, which means that both the reviewer (s) and author (s) identities concealed from the reviewers, and vice versa, throughout the review process. All submitted manuscripts are reviewed by three reviewer one from India and rest two from overseas. There should be proper comments of the reviewers for the purpose of acceptance/ rejection. There should be minimum 01 to 02 week time window for it.

\section{CONCLUSION}

The importance of image recognition is being overlooked and proper use of this technology is not done there should be more system with this image recognition has to be installed so that to overcome the problems faced and so we can save human power and as time as well, the time taken by humans for this work is more and even as there is less human resource available we have to go for some alternative in classification of things and other observation work like security surveillance where there should be proper count of all the events going on and their classification should also be done so for these things this technology is the proper solution and hope our future can be changed by using this technology to its maximum extent.

\section{REFERENCES}

[1] Kumarave A., Rangarajan K.,Algorithm for automaton specification for exploring dynamic labyrinths, Indian Journal of Science and Technology,V-6,I-SUPPL5,PP-4554-4559,Y-2013

[2] P. Kavitha, S. Prabakaran "A Novel Hybrid Segmentation Method with Particle Swarm Optimization and Fuzzy C-Mean Based On Partitioning the Image for Detecting Lung Cancer" International Journal of Engineering and Advanced Technology (IJEAT) ISSN: 2249-8958, Volume-8 Issue-5, June 2019

[3] Kumaravel A., Meetei O.N.,An application of non-uniform cellular automata for efficient cryptography,2013 IEEE Conference on Information and Communication Technologies, ICT 2013,V-,I-,PP-1200-1205,Y-2013

[4] Kumarave A., Rangarajan K.,Routing alogrithm over semi-regular tessellations,2013 IEEE Conference on Information and Communication Technologies, ICT 2013,V-,I-,PP-1180-1184,Y-2013

[5] P. Kavitha, S. Prabakaran "Designing a Feature Vector for Statistical Texture Analysis of Brain Tumor" International Journal of Engineering and Advanced Technology (IJEAT) ISSN: 2249-8958, Volume-8 Issue-5, June 2019

[6] Dutta P., Kumaravel A.,A novel approach to trust based identification of leaders in social networks,Indian Journal of Science and Technology,V-9,I-10,PP--,Y-2016

[7] Kumaravel A., Dutta P.,Application of Pca for context selection for collaborative filtering,Middle - East Journal of Scientific Research,V-20,I-1,PP-88-93,Y-2014

[8] Kumaravel A., Rangarajan K.,Constructing an automaton for exploring dynamic labyrinths,2012 International Conference on Radar, Communication and Computing, ICRCC 2012,V-,I-,PP-161-165,Y-2012

[9] P. Kavitha, S. Prabakaran "Adaptive Bilateral Filter for Multi-Resolution in Brain Tumor Recognition" International Journal of Innovative Technology and Exploring Engineering (IJTTEE) ISSN: 2278-3075, Volume-8 Issue-8 June, 2019

[10] Kumaravel A.,Comparison of two multi-classification approaches for detecting network attacks, World Applied Sciences Journal,V-27,I-11,PP-1461-1465,Y-2013

[11] Tariq J., Kumaravel A.,Construction of cellular automata over hexagonal and triangular tessellations for path planning of multi-robots,2016 IEEE International Conference on Computational Intelligence and Computing Research, ICCIC 2016,V-,I-,PP--,Y-2017

[12] Sudha M., Kumaravel A.,Analysis and measurement of wave guides using poisson method,Indonesian Journal of Electrical Engineering and Computer Science,V-8,I-2,PP-546-548,Y-2017

[13] Ayyappan G., Nalini C., Kumaravel A., Various approaches of knowledge transfer in academic social network, International Journal of Engineering and Technology,V-,I-,PP-2791-2794,Y-2017

[14] Kaliyamurthie, K.P., Sivaraman, K., Ramesh, S. Imposing patient data privacy in wireless medical sensor networks through homomorphic cryptosystems 2016, Journal of Chemical and Pharmaceutical Sciences92.

[15] Kaliyamurthie, K.P., Balasubramanian, P.C. An approach to multi secure to historical malformed documents using integer ripple transfiguration 2016 Journal of Chemical and Pharmaceutical Sciences92.

[16] A.Sangeetha,C.Nalini,"Semantic Ranking based on keywords extractions in the web", International Journal of Engineering \& Technology, 7 (2.6) (2018) 290-292

[17] S.V.GayathiriDevi,C.Nalini,N.Kumar,"An efficient software verification using multi-layered software verification tool "International Journal of Engineering \& Technology, 7(2.21)2018 454-457

[18] C.Nalini,ShwtambariKharabe,"A Comparative Study On Different Techniques Used For Finger - Vein Authentication", International Journal Of Pure And Applied Mathematics, Volume 116 No. 8 2017, 327-333, Issn: 1314-3395

[19] M.S. Vivekanandan and Dr. C. Rajabhushanam, "Enabling Privacy Protection and Content Assurance in Geo-Social Networks", International Journal of Innovative Research in Management, Engineering and Technology, Vol 3, Issue 4, pp. 49-55, April 2018.

[20] Dr. C. Rajabhushanam, V. Karthik, and G. Vivek, "Elasticity in Cloud Computing", International Journal of Innovative Research in Management, Engineering and Technology, Vol 3, Issue 4, pp. 104-111, April 2018.

[21] K. Rangaswamy and Dr. C. Rajabhushanamc, "CCN-Based Congestion Control Mechanism In Dynamic Networks", International Journal of Innovative Research in Management, 
Engineering and Technology, Vol 3, Issue 4, pp. 117-119, April 2018.

22] Kavitha, R., Nedunchelian, R., "Domain-specific Search engine optimization using healthcare ontology and a neural network backpropagation approach", 2017, Research Journal of Biotechnology, Special Issue 2:157-166

[23] Kavitha, G., Kavitha, R., "An analysis to improve throughput of high-power hubs in mobile ad hoc network" ,2016, Journal of Chemical and Pharmaceutical Sciences, Vol-9, Issue-2: 361-363

[24] Kavitha, G., Kavitha, R., "Dipping interference to supplement throughput in MANET", 2016, Journal of Chemical and Pharmaceutical Sciences, Vol-9, Issue-2: 357-360

[25] Michael, G., Chandrasekar, A.,'Leader election based malicious detection and response system in MANET using mechanism design approach", Journal of Chemical and Pharmaceutical Sciences(JCPS) Volume 9 Issue 2, April - June 2016.

[26] Michael, G., Chandrasekar, A.,'Modeling of detection of camouflaging worm using epidemic dynamic model and power spectral density", Journal of Chemical and Pharmaceutical Sciences(JCPS) Volume 9 Issue 2, April - June 2016

[27] Pothumani, S., Sriram, M., Sridhar, J., Arul Selvan, G., Secure mobile agents communication on intranet,Journal of Chemical and Pharmaceutical Sciences, volume 9, Issue 3, Pg No S32-S35, 2016

[28] Pothumani, S., Sriram, M., Sridhar, Various schemes for database encryption-a survey, Journal of Chemical and Pharmaceutical Sciences, volume 9, Issue 3, Pg NoS103-S106, 2016

[29] Pothumani, S., Sriram, M., Sridhar, A novel economic framework for cloud and grid computing, Journal of Chemical and Pharmaceutical Sciences, volume 9, Issue 3, Pg No S29-S31, 2016

[30] Priya, N., Sridhar, J., Sriram, M. "Ecommerce Transaction Security Challenges and Prevention Methods- New Approach” 2016 ,Journal of Chemical and Pharmaceutical Sciences, JCPS Volume 9 Issue 3.page no:S66-S68

[31] Priya, N.,Sridhar,J.,Sriram, M."Vehicular cloud computing security issues and solutions" Journal of Chemical and Pharmaceutical Sciences(JCPS) Volume 9 Issue 2, April - June 2016

[32] Priya, N., Sridhar, J., Sriram, M. "Mobile large data storage security in cloud computing environment-a new approach" JCPS Volume 9 Issue 2. April - June 2016

[33] Anuradha.C, Khanna.V, "Improving network performance and security in WSN using decentralized hypothesis testing "Journal of Chemical and Pharmaceutical Sciences(JCPS) Volume 9 Issue 2, April - June 2016.

[34] Anuradha.C, Khanna.V, "A novel gsm based control for e-devices" Journal of Chemical and Pharmaceutical Sciences(JCPS) Volume 9 Issue 2, April - June 2016

[35] Anuradha.C, Khanna.V, "Secured privacy preserving sharing and data integration in mobile web environments " Journal of Chemical and Pharmaceutical Sciences(JCPS) Volume 9 Issue 2, April - June 2016.

[36] Sundarraj, B., Kaliyamurthie, K.P. Social network analysis for decisive the ultimate classification from the ensemble to boost accuracy rates 2016 International Journal of Pharmacy and Technology 8

[37] Sundarraj, B., Kaliyamurthie, K.P. A content-based spam filtering approach victimisation artificial neural networks 2016 International Journal of Pharmacy and Technology83.

[38] Sundarraj, B., Kaliyamurthie, K.P. Remote sensing imaging for satellite image segmentation 2016 International Journal of Pharmacy and Technology8 3.

[39] Sivaraman, K., Senthil, M. Intuitive driver proxy control using artificial intelligence 2016 International Journal of Pharmacy and Technology84.

[40] Sivaraman, K., Kaliyamurthie, K.P. Cloud computing in mobile technology 2016 Journal of Chemical and Pharmaceutical Sciences92.

[41] Sivaraman, K., Khanna, V. Implementation of an extension for browser to detect vulnerable elements on web pages and avoid click jacking 2016 Journal of Chemical and Pharmaceutical Sciences92.

\section{AUTHORS PROFILE}

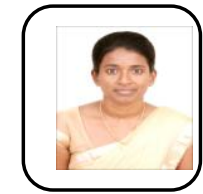

S.Theivasigamani Assistant Professor, Department of Computer Science \& Engineering, Bharath Institute of Higher Education and Research, Chennai, India

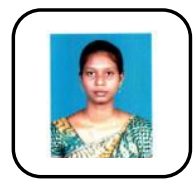

Mary Linda Assistant Professor Department of Computer Science \& Engineering, Bharath Institute of Higher Education and Research, Chennai, India

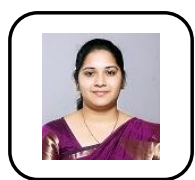

Ms. S. Amudha Assistant Professor, Department of Computer Science \& Engineering, Bharath Institute of Higher Education and Research, Chennai, India 